\title{
Effectiveness of a One-day Simulation-based Program in Psychiatry for Medical Students: A Controlled Study
}

\section{Nadia YOUNES ( $\sim$ nyounes@ch-versailles.fr)}

Université Paris Saclay, Université Versailles Saint Quentin, CESP, Team DevPsy, 94807, Villejuif, France Anne Laure Delaunay

Université Paris Saclay, Université Versailles Saint Quentin, CESP, Team DevPsy, 94807, Villejuif, France

\section{Matthieu Roger}

Université Paris Saclay, Université Versailles Saint Quentin, CESP, Team DevPsy, 94807, Villejuif, France

\section{Pierre Serra}

Université Paris Saclay, Université Versailles Saint Quentin, CESP, Team DevPsy, 94807, Villejuif, France

\section{France Hirot}

Université Paris Saclay, Université Versailles Saint Quentin, CESP, Team DevPsy, 94807, Villejuif, France

\section{Frédéric Urbain}

Département de médecine générale, UFR des sciences de la santé Simone Veil, Université Versailles-

Saint-Quentin-en-Yvelines, Montigny le Bretonneux, France

\section{Nathalie Godart}

Université Paris Saclay, Université Versailles Saint Quentin, CESP, Team DevPsy, 94807, Villejuif, France

\section{Mario Speranza}

Université Paris Saclay, Université Versailles Saint Quentin, CESP, Team DevPsy, 94807, Villejuif, France

\section{Christine Passerieux}

Université Paris Saclay, Université Versailles Saint Quentin, CESP, Team DevPsy, 94807, Villejuif, France

\section{Paul Roux}

Université Paris Saclay, Université Versailles Saint Quentin, CESP, Team DevPsy, 94807, Villejuif, France

\section{Research Article}

Keywords: simulation, standardized patient, psychiatry, medical students, psychometrics, confidence, clinical skills, internal consistency, factor analysis, test-retest reliability

Posted Date: December 28th, 2020

DOl: https://doi.org/10.21203/rs.3.rs-129706/v1 
License: (c) (i) This work is licensed under a Creative Commons Attribution 4.0 International License. Read Full License 


\section{Abstract}

Background: Training in psychiatry requires specific knowledge, attitudes, and skills that are obtainable by simulation, which needs further development for medical students. After an analysis of previous research with medical students, we evaluated the effectiveness of a one-day teaching program in psychiatry by simulation and validated a scale measuring Confidence in Psychiatric Clinical Skills (CPCQ).

Methods: The population was recruited during the 2019-2020 academic year among the 131 fifth-year undergraduate students at the French University of Versailles Saint-Quentin-en-Yvelines-Paris Saclay (the year of compulsory psychiatric training). A controlled study compared knowledge (university grades on the entire national program of psychiatry) and confidence (CPCQ scores) between a control group who received the usual psychiatric instruction and the simulation group who also participated in the simulation program. In the simulation group, satisfaction (including the quality of the debriefing) was investigated. The CPCQ scale was validated by assessing the factor structure, internal consistency, and test-retest reliability.

Results: All fifth-year undergraduate medical students were included: 24 in the simulation group (voluntarily recruited) and 76 in the control group. Their knowledge did not differ before the simulation. After the simulation, knowledge and confidence increased significantly in the simulation group. Two months after the simulation, knowledge and confidence were significantly higher in the simulation group. Satisfaction with the training and debriefing was very high. The CPCQ scale showed good psychometric properties: a single-factor structure, acceptable internal consistency ( $a=0.73[0.65-0.85])$, and good testretest reliability $(\mathrm{ICC}=0.71[0.35-0.88])$.

Several limits were discussed.

Conclusions: Adding a one-day simulation program in psychiatry to the usual teaching improved the knowledge and confidence of medical students even 2 months after. The CPCQ scale could be used for the evaluation of educational programs.

\section{Background}

In Medical Education, the use of the pedagogical method of simulation has increased greatly since the introduction of "Harvey", the cardiology patient simulator, in the 1970s, followed by other experiments in surgery, pediatrics, obstetrics, and anesthesia, and now concerns all medical fields (1). It includes technology-enhanced simulation (virtual reality simulators, mannequin-based simulation, or computer simulation with virtual patients (2)) as well as standardized patients (SPs), notably in psychiatry (3). A major component of experiential learning is the debriefing that follows a simulated or real experience, consisting of a facilitated conversation in which participants analyze their actions, thought process, and emotional states during three stages: reactions, understanding, and summary (4-6). It aims to assess the learners' clinical reasoning patterns and foster thinking patterns from direct experience to later action (7). 
Two methods are well-established: the Debriefing Assessment for Simulation in Healthcare (DASH) (7) and the Objective Structured Assessment Debriefing (OSAD) (8).

In psychiatry, simulation is yet to be developed $(9,10)$. Training in psychiatry requires particularly specific knowledge, attitudes, and skills that cannot simply be learned theoretically without experiential learning. Simulation, which promotes learning by doing and experiencing (11), provides a great opportunity to allow the development of specific communication (12), psychotherapeutic, and clinical skills for the assessment and management of various psychiatric disorders, technical abilities (13) and teamwork skills and interprofessional collaboration (14).

A recent meta-analysis on simulation training in psychiatry for medical students, post-graduate trainees, and qualified doctors reported a threefold increase in research over the past ten years (15). Several universities have introduced such training as compulsory (16) because medical students are demanding it for several reasons. All students, and not only those who want to become psychiatrists, may benefit from such learning because psychiatry is de facto practiced by many physicians, starting with GPs (17). A significant proportion of medical students never participate in a clerkship in psychiatry due to the limited number of places and even for those who do, training may be insufficient $(9,18)$. Simulation could reduce fear and stigmatization. It also avoids the potential inconvenience of inexperienced students interacting with vulnerable individuals and, above all, exposing them to large groups of students $(19,20)$.

The standard reference for the assessment of a learning intervention is Kirkpatrick's Training Evaluation Model (21), which measures the impact on five levels: 1) reaction effect: satisfaction/dissatisfaction of participants; 2) learning effect: participants improve their knowledge and change their attitudes, skills, or confidence; 3) behavioral effect: transfer of knowledge, skills and abilities in the everyday practice with patients; 4) patient results; and 5) return of investment (22-24). The meta-analysis showed the global effectiveness of simulation training in psychiatry on attitudes, skills, knowledge, and satisfaction (15). We analyzed the results for medical students (48 surveys, 16 RCTs, and 32 controlled studies, 10 with follow-up). A positive impact on satisfaction was reported for level 1 in seven studies $(25,26)$, without any evaluation of the satisfaction with the debriefing. For level 2, an improvement in student's objective knowledge after simulation relative to other pedagogical methods was reported in 14 studies (and none in 6), often for substance use disorders $(27,28)$. Other domains of psychiatry need to be investigated and only $\mathrm{N}=8$ studies investigated the impact at a distance from the time of the intervention. $\mathrm{N}=27$ studies assessed self-reported attitudes: $\mathrm{N}=15$ confidence (without a validated tool), $\mathrm{N}=10$ attitudes, $\mathrm{N}=2$ empathy and $\mathrm{N}=1$ the Malash Burnout Inventory. A positive impact on self-reported attitudes and confidence was reported in twenty studies and any in seven. $\mathrm{N}=17$ studies rated communication skills with standardized patients by independent blinded researchers, approaching an evaluation of the transfer of knowledge and skills (level 3), but they still remained in standardized situations and did not reach the everyday clinical practice. 10 reported an improvement and 7 any $(22,29,30)$. Levels 3,4 and 5 were not investigated yet. 
We developed and evaluated an intervention for medical students with three features: 1) one-day program, 2) coordination between teachers of psychiatry for adults, children, and adolescents and those of general medicine, and 3) presentation of common situations encountered in daily practice in primary care or in the emergency room. We also developed a scale to measure the learners' confidence in their psychiatric clinical skills. Examining one's own practices is a fundamental dimension to characterize skills and clinical performance (31)'(32). No tool was suitable for our study. Confidence scales from nursing education with excellent psychometric properties (33-35) were not adapted for medical students. General self-assessment scales of psychiatric competence did not study their psychometric properties $(36,37)$. Finally, confidence scales with satisfactory internal consistency but specific to certain clinical situations, such as suicidal risk (38-40) and depression (22)) could not be used for our clinical situations.

The present study thus had two objectives: 1) to evaluate the effectiveness of the one-day simulation program for medical students in terms of level 1 and 2 in Kirkpatrick's Training Evaluation Model: satisfaction (including satisfaction with the debriefing), knowledge and self-confidence in clinical skills and changes in professional practices two months after the program and 2) to explore the psychometric properties of a new self-report questionnaire on confidence in one's clinical skills in psychiatry.

\section{Methods}

\section{Design}

The study had a mixed design, with comparisons of before and after the intervention and between the intervention and control groups (figure 1).

\section{Population}

The population was recruited during the 2019-2020 academic year among the 131 fifth-year undergraduate students at the University of Versailles Saint-Quentin-en-Yvelines-Paris Saclay (the year of compulsory psychiatric training).

\section{Intervention}

The intervention consisted of one day ( 8 hours) of teaching of psychiatry by simulation with a simulated patient. The scenarios, decided within a group of 10 hospital-university teachers (from university fellow to professor in general medicine, child and adolescent psychiatry, or adult psychiatry), had to be: 1) addressed in the curriculum of the official national program (41), 2) a pathology frequently encountered in general practice, and 3 ) realistically performed by a team of psychiatry teachers not trained in acting (eliminating the scenario of schizophrenia, which is challenging to play (15)). The four scenarios presented a drug suicide attempt in the context of borderline personality disorder and alcohol addiction assessed in the emergency room by a psychiatrist and bereavement associated with post-traumatic 
stress disorder, hypomania, and a refusal to go to school by a 14-year-old adolescent assessed in a general-practice setting.

Each simulation session included a briefing (10 min), the simulation (10-20 min), a structured debriefing (45 $\mathrm{min}$ ), and a theoretical synthesis slide presentation (20 min). Learners were divided into groups of eight (2 actively participating, 6 watching the live video broadcast in an adjacent room). Three teachers were involved, one playing the role of the patient, one as a potential facilitator, and one staying with the learners.

No randomization was used to assign the intervention or control group status. Students in the intervention group were recruited voluntarily and accepted an optional teaching unit on the condition that they actively participated in one scenario. The control group, recruited from non-participating students, received the same usual psychiatric instruction as the simulation group in the form of a compulsory twoday interactive seminar with the technique of the flipped classroom (42). All fifth-year undergraduate students were provided with the pedagogical written content of the simulation sessions to ensure that any differences between the groups were related to the simulation teaching technique itself.

\section{Measures}

\section{1) Knowledge}

Theoretical knowledge was measured using multiple choice questions (MCQs) three times: for all students, two months before the simulation teaching ( 45 questions before the compulsory psychiatry seminar) and two months after (50 MCQs during the psychiatry examination, covering the entire national program of psychiatry for the university grade) and for the simulation group, before and after the teaching (28 questions). All scores were scaled from 0 to 20.

\section{2) Confidence (Supplementary Information 1)}

Confidence was assessed by the specifically created Confidence in Psychiatric Clinical skills Questionnaire (CPCQ): 12 items, rated on a four-level Likert scale, explored confidence in theoretical knowledge, clinical skills (clinical reasoning and psychiatric interviewing), communication and interpersonal skills (with the patient, the patient's proxies, and other professionals), and the management of psychiatric disorders. The individual mean score was used in the analyses.

The change in professional practice was evaluated with one question: "How much do you think this teaching of simulation psychiatry will improve your future practice? " It was rated on a 4-level Likert scale ranging from "very unimportant" (coded 1) to "very important" (coded 4).

3) Satisfaction (Supplementary Information 2 and 3)

General satisfaction was rated out of 10. A 10-item questionnaire, rated on a four-level Likert scale, explored various aspects of satisfaction, such as the preference for simulation over another pedagogical 
modality, the perceived realism of the situation, the importance of being actively involved, etc. In addition, learners who underwent a clerkship in psychiatry were asked to compare it to the simulation. Questions about the scenarios and free comments were collected.

Satisfaction with the briefing and debriefing was assessed using the student version of the DASH(43). This scale, with excellent internal consistency (0.82-0.95) (44-46), explores the climate, structure of the debriefing, ability to engage in exchange, and strengths and areas for improvement. The mean across all items ( 6 overall assessments, 23 behavioral assessments) was used.

\section{Statistical analysis}

\section{Comparisons between simulation and control groups}

First, age and participation in a clerkship in psychiatry (a potential confounding factor for confidence (39)) were compared between the two groups using chi $^{2}$ tests and scores on the pre-requisite exam using Student's t-test. Analyses of covariance (ANCOVA) was then carried out with the mean CPCQ score and the psychiatry final exam score as dependent variables, the group as the independent variable, and the covariates that differed significantly between the two groups (clerkship in psychiatry).

\section{Pre/post-simulation comparisons}

The average CPCQ and knowledge test scores just before and after simulation were compared using paired sample Student t-tests. Satisfaction was measured post-stimulation.

\section{Psychometric characteristics of the CPCQ scale}

Construct validity was explored by exploratory factor analysis using oblim rotation and maximum likelihood factorization as the factorization method. Two criteria were used to determine the number of significant factors: first, Catell's scree test, i.e. factors present to the left of the eigenvalue curve deflection (47), and second, Kaiser's criteria, i.e. factors for which the eigenvalue is $>1$ (48). The internal consistency of each identified factor was evaluated using Cronbach's a coefficient(49), with an acceptability threshold set to 0.7 (50). These analyses were carried out on the largest sample for the same time of measurement (final exam) and by bringing the two groups together.

Test-retest reliability was assessed by the intra-class correlation coefficient (ICC), calculated using a mixed model with a random double effect. It was defined as poor for an ICC $<0.4$, acceptable between 0.4 and 0.59 , good between 0.6 and 0.74 , and excellent between 0.75 and 1(51). The two times of measurement chosen to calculate it were those for which the least possible change was expected, i.e. just after the simulation and two months later. 


\section{Number of required subjects}

The number of required subjects was calculated for knowledge (score out of 20 on the usual psychiatric examination). According to the results of the previous year, the average score was 13.3, with a standard deviation of 1.9. To show a mean difference of 2 points with an alpha risk of $5 \%$ and a statistical power of $90 \%$ required at least 19 subjects per group.

\section{Ethics statement}

The research was authorized on 20/12/2010 by the Ethics Committee of the University of Paris-Saclay (CER-Paris-Saclay-2019-061). All participants signed written and informed consent.

\section{Results}

\section{Participants}

The 24 places available for the simulation were filled within a few days of the opening of registration and all learners agreed to participate in the research. In the control group, 76 among 107 students $(71.0 \%)$ consented to participate in the research.

The simulation and control groups did not differ in terms of either the sex ratio $\left(X^{2}=0, p=0.93\right)$ or initial knowledge $(\mathrm{t}(97)=1.2, \mathrm{p}=0.24)$. There were more students with a clerkship in psychiatry in the intervention group $\left(X^{2}=3.7, p=0.056\right)$.

\section{Knowledge}

The ANCOVA showed better theoretical knowledge on the psychiatry exam $(F(1.96)=6, p=0.016)$ in the simulation group than in the control group.

Theoretical knowledge $(t(23)=2.6, p=0.01)$ improved after teaching.

\section{Confidence}

The ANCOVA showed higher confidence on the CPCQ scale $(F(1.89)=6, p=0.003)$ for the simulation group than the control group.

Confidence measured with the CPCQ scale improved after teaching (t $(23)=8.2, p<0.001)$. Learners shifted from an average low confidence level $(2.2 \pm$ SD 0.3$)$ before instruction to an average high confidence level $(2.7 \pm 0.2)$ afterwards. This gain was maintained for two months, insofar as the reassessment of confidence with the CPCQ scale was not significantly different between immediately after the simulation and two months later $(t(15)=0.7, p=0.52)$. 
Students in the intervention reported on average that it will change their future practice in a way "important" or "very important" (3.4 \pm SD 0.5).

\section{Satisfaction}

The overall satisfaction score was excellent (9.3 +-SD 0.6). The average scores on the satisfaction questionnaire (3.5 \pm SD 0.2) showed that learners were satisfied to very satisfied with the teaching. The lowest score was obtained on the question about optional or compulsory teaching "( $2.7 \pm$ SD 0.8$)$, suggesting a neutral position for the group of learners. The highest score was obtained for the questions on preference of courses rather than the simulation ( $3.9 \pm$ SD 0.3$)$, and on the realism of the simulations (3.8 \pm SD 0.4). All learners who had a clerkship in psychiatry felt that the simulation was more $(4 / 5)$ or much more (1/5) informative that the clerkship.

The level of difficulty was found to be appropriate on average (3.1 \pm SD 0.2$)$. The scenarios were judged to be informative or very informative (3.5 \pm SD 0.4$)$.

Free comments were positive and suggested areas for improvement (summarizing an ideal psychiatric interview, furthering theoretical reminders, including other pathologies, such as eating disorders and schizophrenia).

The average total DASH score showed the briefing and debriefing of the simulation sessions to be rated as very good (6.5 \pm SD 0.4 ). Behavioral scores suggested a good sense of security for the learners.

\section{Psychometric characteristics of the CPCQ scale}

\section{Factor structure}

A scree diagram (Figure 2) showed a single-factor structure of the CPCQ scale according to the Catell criterion, as the deflection of the curve occurred for two factors. The first factor was the only one with an eigenvalue $>1$ (Kaiser criterion) and accounted for $20.5 \%$ of the variance.

\section{Internal consistency}

With a Cronbach's alpha coefficient of 0.73 [0.65 - 0.85], the internal consistency was satisfactory.

\section{Test-retest reliability}

The ICC, equal to 0.71 [0.35 - 0.88], suggests good test-retest reliability. 


\section{Discussion}

We evaluated the effectiveness of a one-day simulation program with standardized patients for medical students as a complement to usual teaching. There was improvement after simulation for knowledge and confidence. Satisfaction, including that concerning the debriefing, was high.

The effectiveness in improving knowledge of our one-day simulation training in psychiatry is coherent with previous results with medical students (15). The positive impact was maintained a few months after the training $(27,28,52,53)$. This difference may be due to higher pedagogical time spent with the intervention students (one day) (54). But simulation in psychiatry may also allow, as an addition to other pedagogical tools, sustainable acquisition of knowledge that cannot be simply learned theoretically and memorized without experiential learning (11). All participants who had a clerkship in psychiatry and the simulation, found the latter to be more informative. Simulation with a standardized patient provides an opportunity for real-time feedback and reflection on performance, which is rarely the case in interactions between medical students and people with psychiatric disorders (10).

The improvement in confidence is also consistent with the results of the majority of previous studies on medical students (15). This is the first study to report that the improvement in self-confidence is maintained two months after receiving the training. Among attitudes, self-confidence is that which has been the most explored relative to empathy or stigmatization (15), and has been associated with better skills, for example in assessing suicide risk (32).

Simulation is popular among students. Our study confirmed a very high level of satisfaction with the content of the teaching and its usefulness for practice. The average DASH score, well above the usual acceptability threshold of four (46), suggests effective briefings and debriefings in a safe educational framework. Despite the lack of teachers trained to act, the simulations appeared to be realistic to the learners. Future studies could use validated scales, such as the Maastricht Assessment of Simulated Patients (55), to reliably assess the quality of standardized patient role-play.

Our study had several limitations, despite a relatively high median quality, as assessed by the MERSQI (Medical Education Research Study Quality Instrument), i.e. 12 (Supplementary Information 4) vs 10.8 for studies reported in the meta-analysis (15). The main limitation was, as in most previous studies (15), the absence of random assignment, which is difficult in the context of elective teaching based on learner preferences. The higher proportion of learners with a clerkship in psychiatry in the simulation group may suggest a selection bias toward individuals with a high level of interest and motivation for the discipline. Second, some measures were missing: prior exposure to simulation experiments for both groups and a measure of pre-intervention confidence for the control group (the simulation group may have had a higher level of confidence than the control group prior to the intervention, in connection with participation in a clerkship in psychiatry). Third, the generalizability of our results is limited by the small sample size and a single teaching site. Fourth, we did not explore levels 3 and 4 of Kirkpatrick's model for simulation, i.e. the transfer of knowledge and skills in clinical practice outcome on management and individuals with a mental disorder. This would be important to judge whether wider dissemination of this pedagogical 
technique in the mental health field would be pertinent. We did not find a validated scale to assess skill in psychiatry, despite the efforts of certain authors to develop objective measures of the efficiency of a psychiatric interview (56), and an assessment by teachers was not possible, as the students participated in the simulation only once.

The CPCQ scale of the confidence of medical students' clinical skills in psychiatry showed satisfactory psychometric properties (acceptable internal consistency, good test-retest reliability, and a unifactorial structure) and it proved to be an easy and rapid evaluation tool. It is an important addition to tools for which the psychometric properties are not known(57). Given the small sample size for measuring testretest reliability, the confidence interval obtained was large and the results should be replicated on a larger sample.

\section{Conclusion}

Our study shows the effectiveness in terms of knowledge gained, confidence, and satisfaction of a oneday program of teaching psychiatry through standardized patient-based simulation as a complement to usual teaching for fifth-year medical students in France. The teaching has the disadvantage of being resource-intensive (58), especially in terms of human resources, with a teacher/learner ratio of $3 / 8$ and we did not measure its impact or not on behavioral effect in the everyday practice with patients and on patient results. The Confidence in Psychiatric Clinical Competence Scale shows acceptable psychometric properties and may be used by other educational teams involved in teaching psychiatry to medical students.

\section{Abbreviations}

MCQ: multiple-choice questions

CPCQ Questionnaire: Confidence in Psychiatric Clinical Skills Questionnaire

DASH: evaluation of debriefing for health simulation

ICC: intra-class correlation coefficient

ANCOVA: analyses of covariance

\section{Declarations}

\section{Ethics approval and consent to participate}

The research was authorized on 12/20/2010 by the Ethics Committee of the University of Paris-Saclay under the reference CER-Paris-Saclay-2019-061. All participants signed a written informed consent form before being included in the study. 


\section{Consent for publication}

Not applicable.

\section{Availability of data and materials}

Anonymous data used and analyzed in this study are available upon request.

\section{Competing interest}

The authors have no conflict of interest to declare.

\section{Funding}

This research received no specific grant from any funding agency in the public, commercial, or not-forprofit sectors. We thank the Centre Hospitalier de Versailles for editorial assistance.

\section{Authors' contributions}

PR designed the study and performed the data analysis. NY and PR drafted the manuscript. NY, ALD, MR, PS, FH, FU, NG, MS, CP, and PR made critical revisions and edited the manuscript. All authors reviewed the manuscript.

\section{Statement}

All methods were carried out in accordance with relevant guidelines and regulations

\section{Data availability statements}

The datasets used and analysed during the current study are available from the corresponding author on reasonable request.

\section{Acknowledgements}

We thank Franck Abitbol, a simulation technician, and Valéria Martinez, president of the Simulation Committee of the University of Versailles Saint-Quentin-En-Yvelines.

\section{References}

1. Harden RM. Trends and the future of postgraduate medical education. Emerg Med J EMJ. oct 2006;23(10):798-802.

2. Cook DA, Hatala R, Brydges R, Zendejas B, Szostek JH, Wang AT, et al. Technology-enhanced simulation for health professions education: a systematic review and meta-analysis. JAMA. 7 sept 2011;306(9):978-88. 
3. Abdool PS, Nirula L, Bonato S, Rajji TK, Silver IL. Simulation in Undergraduate Psychiatry: Exploring the Depth of Learner Engagement. Acad Psychiatry J Am Assoc Dir Psychiatr Resid Train Assoc Acad Psychiatry. avr 2017;41(2):251-61.

4. Abatzis VT, Littlewood KE. Debriefing in Simulation and Beyond. Int Anesthesiol Clin. 2015;53(4):151-62.

5. Levett-Jones T, Lapkin S. A systematic review of the effectiveness of simulation debriefing in health professional education. Nurse Educ Today. juin 2014;34(6):e58-63.

6. Rudolph JW, Simon R, Raemer DB, Eppich WJ. Debriefing as formative assessment: closing performance gaps in medical education. Acad Emerg Med Off J Soc Acad Emerg Med. nov 2008;15(11):1010-6.

7. Brett-Fleegler M, Rudolph J, Eppich W, Monuteaux M, Fleegler E, Cheng A, et al. Debriefing assessment for simulation in healthcare: development and psychometric properties. Simul Healthc $J$ Soc Simul Healthc. oct 2012;7(5):288-94.

8. Arora A, Ahmed M, Sevdalis N. Evidence-based performance debriefing for surgeons and surgical teams: the Observational Structured Assessment of Debriefing tool (OSAD) [Internet]. 2015 [cité 17 juill 2020]. Disponible sur: https://www.imperial.ac.uk/media/imperial-college/medicine/surgerycancer/pstrc/debriefingosadtool.pdf

9. McNaughton N, Ravitz P, Wadell A, Hodges BD. Psychiatric education and simulation: a review of the literature. Can J Psychiatry Rev Can Psychiatr. févr 2008;53(2):85-93.

10. Dave S. Simulation in psychiatric teaching. Adv Psychiatr Treat R Coll Psychiatr J Contin Prof Dev. 2018/01/02 éd. 2012;18(4):292-8.

11. Clapper TC. Beyond Knowles: What Those Conducting Simulation Need to Know About Adult Learning Theory. Clin Simul Nurs. 1 janv 2010;6(1):e7-14.

12. Neale J. What is the evidence for the use of simulation training to teach communication skills in psychiatry? Evid Based Ment Health. févr 2019;22(1):23-5.

13. Rabheru K, Wiens A, Ramprasad B, Bourgon L, Antochi R, Hamstra SJ. Comparison of traditional didactic seminar to high-fidelity simulation for teaching electroconvulsive therapy technique to psychiatry trainees. J ECT. déc 2013;29(4):291-6.

14. Attoe C, Kowalski C, Fernando A, Cross S. Integrating mental health simulation into routine healthcare education. Lancet Psychiatry. août 2016;3(8):702-3.

15. Piot M-A, Dechartres A, Attoe C, Jollant F, Lemogne C, Layat Burn C, et al. Simulation in psychiatry for medical doctors: A systematic review and meta-analysis. Med Educ. 3 avr 2020;

16. Himmelbauer M, Seitz T, Seidman C, Loffler-Stastka H. Standardized patients in psychiatry - the best way to learn clinical skills? BMC Med Educ. 6 avr 2018;18(1):72.

17. Regier DA, Goldberg ID, Taube CA. The de facto US mental health services system: a public health perspective. Arch Gen Psychiatry. juin 1978;35(6):685-93. 
18. Abed R, Teodorczuk A. Danger ahead: challenges in undergraduate psychiatry teaching and implications for community psychiatry. Br J Psychiatry J Ment Sci. févr 2015;206(2):89-90.

19. Brenner AM. Uses and limitations of simulated patients in psychiatric education. Acad Psychiatry J Am Assoc Dir Psychiatr Resid Train Assoc Acad Psychiatry. avr 2009;33(2):112-9.

20. Eagles JM, Calder SA, Nicoll KS, Walker LG. A comparison of real patients, simulated patients and videotaped interview in teaching medical students about alcohol misuse. Med Teach. sept 2001;23(5):490-3.

21. Kirkpatrick D, Kirkpatrick J. Evaluating training programs: The four levels. Berrett-Koehler Publishers; 2006.

22. Piette A, Muchirahondo F, Mangezi W, Iversen A, Cowan F, Dube M, et al. « Simulation-based learning in psychiatry for undergraduates at the University of Zimbabwe medical school ». BMC Med Educ. 21 févr 2015;15:23.

23. Kameg K, Howard VM, Clochesy J, Mitchell AM, Suresky JM. The impact of high fidelity human simulation on self-efficacy of communication skills. Issues Ment Health Nurs. mai 2010;31(5):315-23.

24. Szpak JL, Kameg KM. Simulation Decreases Nursing Student Anxiety Prior to Communication With Mentally III Patients. Clin Simul Nurs. 1 janv 2013;9(1):e13-9.

25. Gay TL, Himle JA, Riba MB. Enhanced ambulatory experience for the clerkship: curriculum innovation at the University of Michigan. Acad Psychiatry J Am Assoc Dir Psychiatr Resid Train Assoc Acad Psychiatry. 2002;26(2):90-5.

26. Krahn LE, Bostwick JM, Sutor B, Olsen MW. The Challenge of Empathy: A Pilot Study of the Use of Standardized Patients to Teach Introductory Psychopathology to Medical Students. Acad Psychiatry J Am Assoc Dir Psychiatr Resid Train Assoc Acad Psychiatry. mars 2002;26(1):26-30.

27. Kahan M, Wilson L, Midmer D, Borsoi D, Martin D. Randomized controlled trial on the effects of a skills-based workshop on medical students' management of problem drinking and alcohol dependence. Subst Abuse. mars 2003;24(1):5-16.

28. Monteiro K, Dumenco L, Collins S, Bratberg J, MacDonnell C, Jacobson A, et al. An interprofessional education workshop to develop health professional student opioid misuse knowledge, attitudes, and skills. J Am Pharm Assoc JAPhA. avr 2017;57(2S):S113-7.

29. Elley CR, Clinick T, Wong C, Arroll B, Kennelly J, Doerr H, et al. Effectiveness of simulated clinical teaching in general practice: randomised controlled trial. J Prim Health Care. 1 déc 2012;4(4):281-7.

30. Fiedorowicz JG, Tate J, Miller AC, Franklin EM, Gourley R, Rosenbaum M. A medical interviewing curriculum intervention for medical students' assessment of suicide risk. Acad Psychiatry $\mathrm{J}$ Am Assoc Dir Psychiatr Resid Train Assoc Acad Psychiatry. nov 2013;37(6):398-401.

31. Way R. Assessing clinical competence. Emerg Nurse J RCN Accid Emerg Nurs Assoc. févr 2002;9(9):30-4.

32. Mackelprang JL, Karle J, Reihl KM, Cash REG. Suicide Intervention Skills: Graduate Training and Exposure to Suicide among Psychology Trainees. Train Educ Prof Psychol. mai 2014;8(2):136-42. 
33. Flinkman M, Leino-Kilpi H, Numminen O, Jeon Y, Kuokkanen L, Meretoja R. Nurse Competence Scale: a systematic and psychometric review. J Adv Nurs. mai 2017;73(5):1035-50.

34. Grundy SE. The confidence scale: development and psychometric characteristics. Nurse Educ. févr 1993;18(1):6-9.

35. Ewalds-Kvist B, Algotsson M, Bergstrom A, Lutzen K. Psychiatric nurses' self-rated competence. Issues Ment Health Nurs. juill 2012;33(7):469-79.

36. Ajaz A, David R, Bhat M. The PsychSimCentre: teaching out-of-hours psychiatry to non-psychiatrists. Clin Teach. févr 2016;13(1):13-7.

37. Wand A, Maheshwari R, Holton M. Mindful of the gaps: enhancing psychiatry training through a trainee workshop. Australas Psychiatry Bull R Aust N Z Coll Psychiatr. juin 2012;20(3):231-6.

38. Mitchell SM, Taylor NJ, Jahn DR, Roush JF, Brown SL, Ries R, et al. Suicide-Related Training, SelfEfficacy, and Mental Health Care Providers' Reactions Toward Suicidal Individuals. Crisis. 10 janv 2020;1-8.

39. Patel S, Batterham PJ, Calear AL, Cryer R. Predictors of Comfort and Confidence Among Medical Students in Providing Care to Patients at Risk of Suicide. Acad Psychiatry J Am Assoc Dir Psychiatr Resid Train Assoc Acad Psychiatry. déc 2016;40(6):919-22.

40. Pisani AR, Cross WF, Watts A, Conner K. Evaluation of the Commitment to Living (CTL) curriculum: a 3-hour training for mental health professionals to address suicide risk. Crisis. 1 janv 2012;33(1):30-8.

41. AESP, CNUP, CUNEA. Référentiel de Psychiatrie et d'Addictologie Psychiatrie de l'adulte. Psychiatrie de l'enfant et de l'adolescent. Addictologie. Presse Universitaire François-Rabelais; 2016. 592 p. (L'OFFICEL ECN).

42. Hew KF, Lo CK. Flipped classroom improves student learning in health professions education: a meta-analysis. BMC Med Educ. 15 mars 2018;18(1):38.

43. Simon R, Raemer D, Rudolph J. Debriefing Assessment for Simulation in Healthcare@-Student Version, Long Form. Camb Cent Med Simul. 2010;

44. Dreifuerst KT. Using debriefing for meaningful learning to foster development of clinical reasoning in simulation. J Nurs Educ. juin 2012;51(6):326-33.

45. Roh YS, Jang KI. Survey of factors influencing learner engagement with simulation debriefing among nursing students. Nurs Health Sci. déc 2017;19(4):485-91.

46. Brown DK, Wong AH, Ahmed RA. Evaluation of simulation debriefing methods with interprofessional learning. J Interprof Care. 19 juill 2018;1-3.

47. Dmitrienko A, Chuang-Stein C, D'Agostino Sr RB. Pharmaceutical statistics using SAS: a practical guide. SAS Institute; 2007.

48. Kaiser HF. The application of electronic computers to factor analysis. Educ Psychol Meas. 1960;20(1):141-51.

49. Cronbach LJ. Coefficient alpha and the internal structure of tests. Psychometrika. 1951;16(3):297-334. 
50. Bland JM, Altman DG. Statistics notes: Cronbach's alpha. BMJ. British Medical Journal Publishing Group 1997;314(7080):572.

51. Cicchetti DV. Guidelines, criteria, and rules of thumb for evaluating normed and standardized assessment instruments in psychology. Psychol Assess. 1994;6(4):284.

52. Fisher JM, Walker RW. A new age approach to an age old problem: using simulation to teach geriatric medicine to medical students. Age Ageing. mai 2014;43(3):424-8.

53. Albright G, Adam C. Simulated Conversations with Virtual Patients to Prepare Health Professionals to Conduct Screening \& Brief Intervention (SBI) for Substance Use and Mental Health. 2016 [cité 18 juill 2020]; Disponible sur: https://kognito.com/wp-content/uploads/At-

Risk_in_Primary_Care_KognitoResearch_2016.pdf

54. Cook DA. If you teach them, they will learn: why medical education needs comparative effectiveness research. Adv Health Sci Educ Theory Pract. aout 2012;17(3):305-10.

55. Wind LA, Van Dalen J, Muijtjens AMM, Rethans J-J. Assessing simulated patients in an educational setting: the MaSP (Maastricht Assessment of Simulated Patients). Med Educ. janv 2004;38(1):39-44.

56. Pham-Dinh C, Laprevote V, Schwan R, Pichene C, Kabuth B, Braun M, et al. Quantifying efficacy of investigation during a simulated psychiatric interview. L'Encephale. 12 sept 2019;

57. Hodges B, Hanson M, McNaughton N, Regehr G. Creating, monitoring, and improving a psychiatry OSCE: a guide for faculty. Acad Psychiatry J Am Assoc Dir Psychiatr Resid Train Assoc Acad Psychiatry. Autumn 2002;26(3):134-61.

58. Pheister M, Stagno S, Cotes R, Prabhakar D, Mahr F, Crowell A, et al. Simulated Patients and Scenarios to Assess and Teach Psychiatry Residents. Acad Psychiatry J Am Assoc Dir Psychiatr Resid Train Assoc Acad Psychiatry. févr 2017;41(1):114-7.

\section{Tables}

Table 1. Comparison of the Simulation group $(N=24)$ and Control group $(N=76)$ among the 131 fifthyear medical students at the University of Versailles Saint-Quentin-En-Yvelines for characteristics, knowledge, attitudes (confidence, change in professional practice) and satisfaction in the simulation group. 


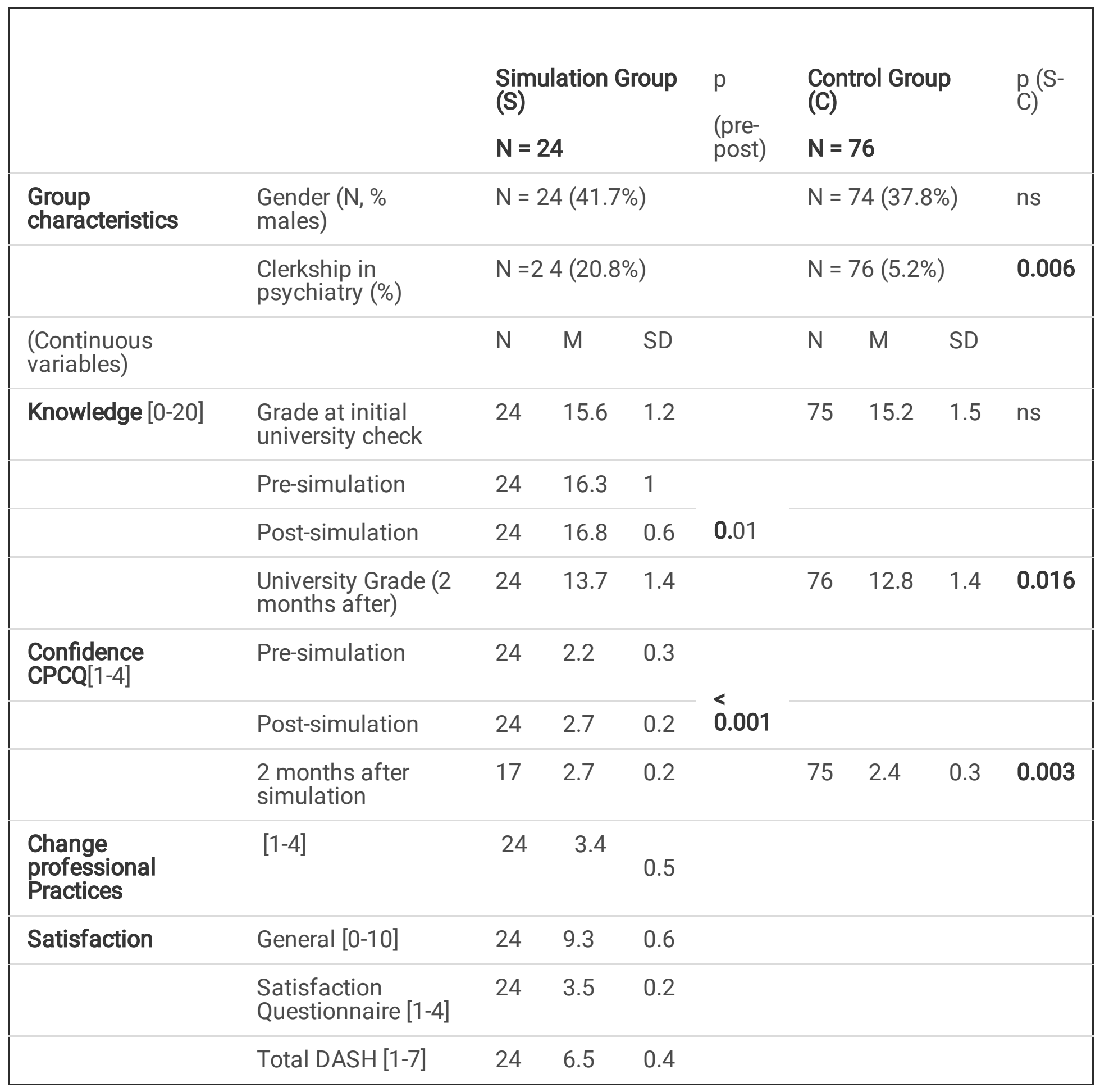

M: mean, SD: standard deviation, CPCQ: Confidence in Psychiatric Clinical skills Questionnaire

\section{Figures}




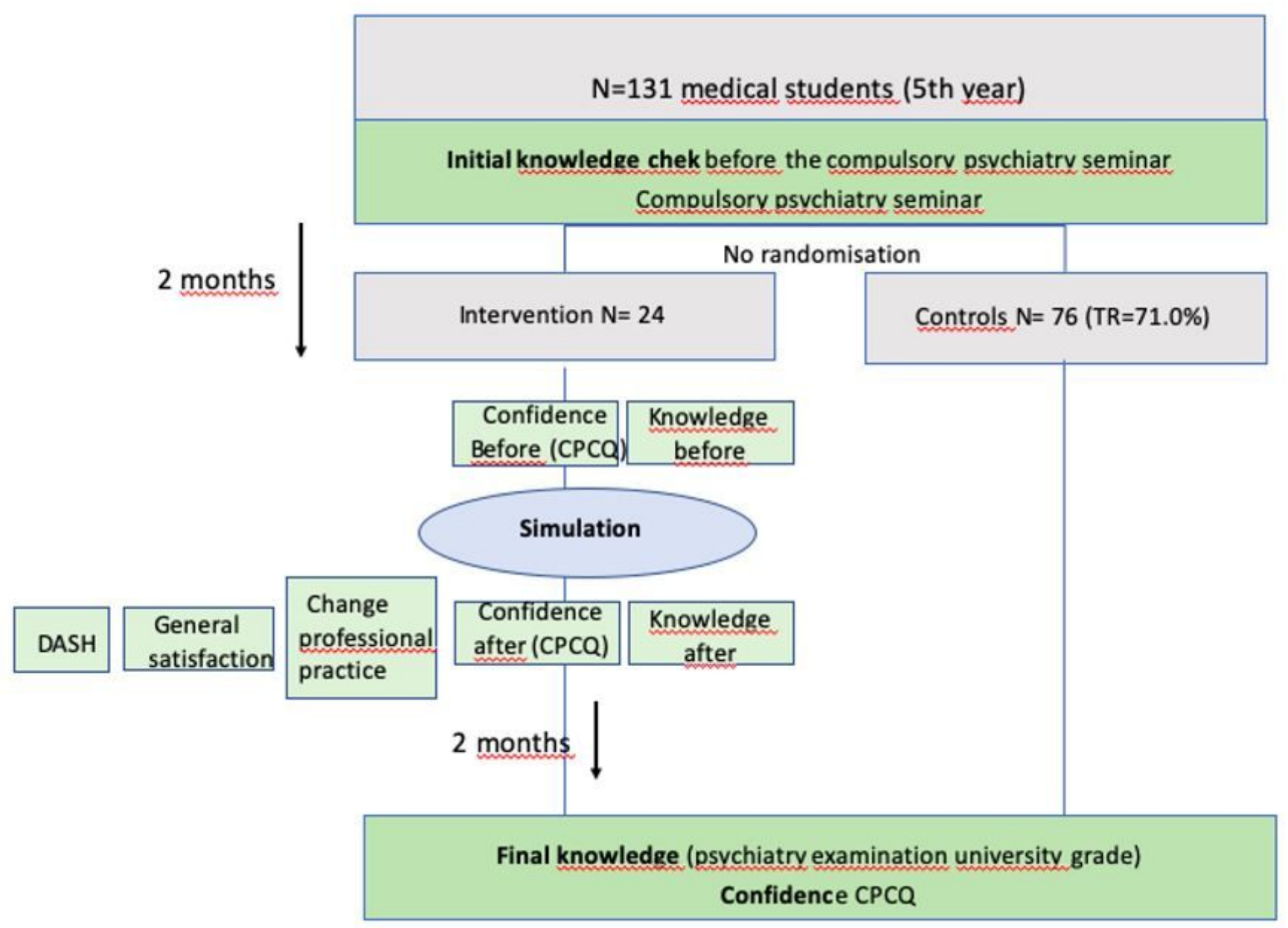

Figure 1

Design of the study 
Eigenvalues of the factors

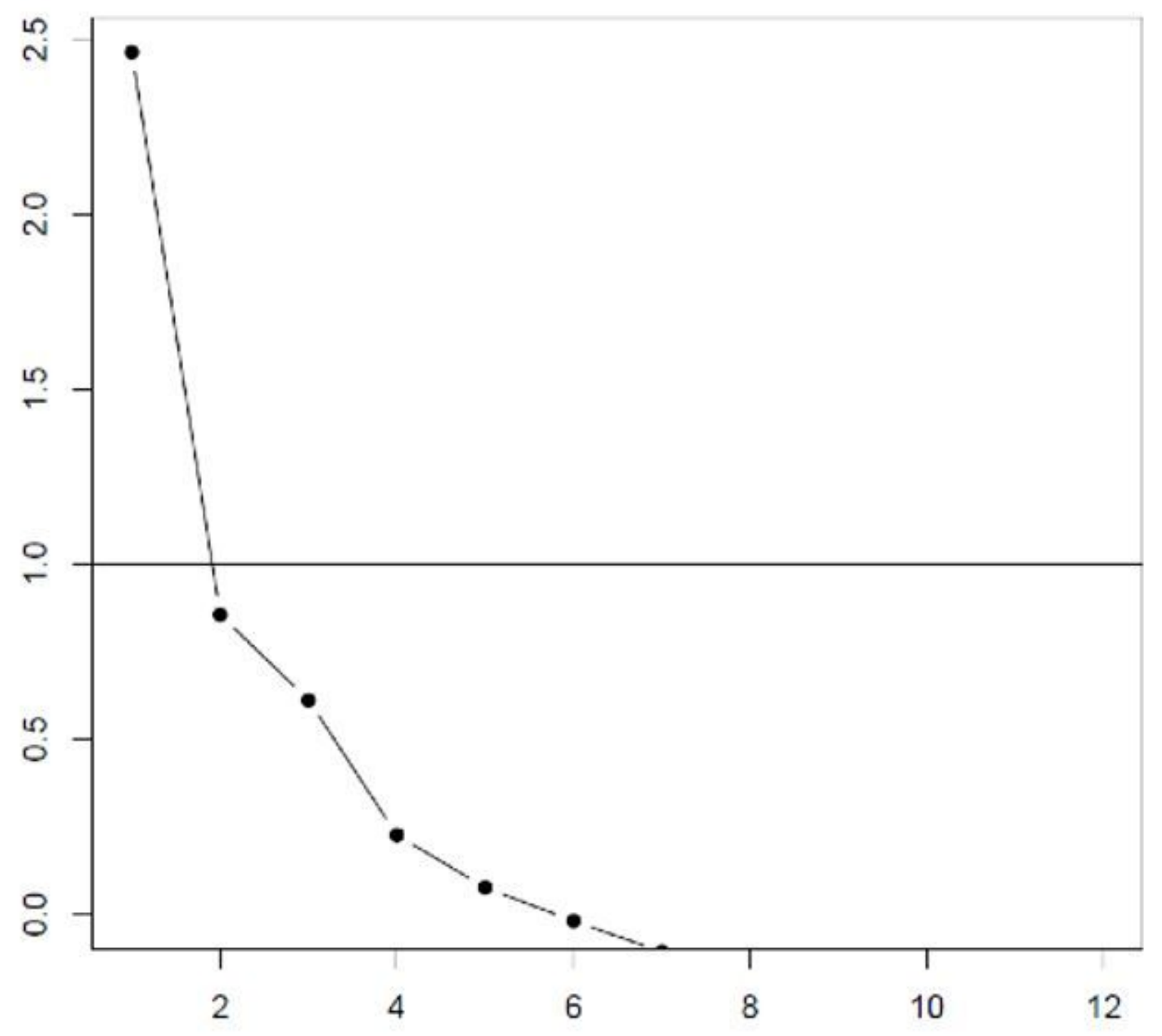

Number of factors

Figure 2

Slump Diagram of the Confidence in Psychiatric Clinical Skills scale

\section{Supplementary Files}

This is a list of supplementary files associated with this preprint. Click to download. 
- Supplementarylnformation1.docx

- Supplementarylnformation2.docx

- Supplementarylnformation3.docx

- Supplementarylnformation4.docx 